\title{
FACTORES SOCIOCULTURALES EN LA EDUCACIÓN SUPERIOR: APROXIMACIÓN A SU ANÁLISIS PARA LA INTERVENCIÓN E INVESTIGACIÓN PEDAGÓGICA
}

\author{
María del Carmen Llontop Castillo / Gloria Pozo Neira \\ Universidad Ricardo Palma \\ llontopcastillo@gmail.com / galmaster@hotmail.com
}

\section{RESUMEN}

La presente investigación busca comprender y explicar los problemas socioculturales que afectan el rendimiento en el nivel universitario de los estudiantes extranjeros que se insertan en el Programa de Estudios Básicos de la Universidad Ricardo Palma, específicamente en el primer ciclo y sobre todo de aquellos que estuvieron matriculados en el Taller de Comunicación Oral y Escrita; para lo cual se toma como base teórica los siguientes modelos: el de la competencia cultural de McCarthy (1994), el sociolingüístico o el de los estilos de comunicación-interacción de David Poveda (2001) y el modelo ecológico de John Ogbu (1993).

\section{PALABRAS CLAVE}

Minoría / Mayoritarios / Cultura dominante / Intercultural / Etnografía.

\section{ABSTRACT}

This research seeks to understand and explain the social and cultural issues affecting performance at university level for foreign students that are inserted into the Core Curriculum at the University Ricardo Palma, specifically in the first cycle and especially those who were enrolled Workshop on Oral and Written Communication; for which it is taken as theoretical basis the following models: the cultural competence of McCarthy (1994), the sociolinguistic or styles of communication-interaction David Poveda (2001) and the ecological model of John Ogbu (1993).

\section{KEY WORDS}

Minority / Majority / Dominant culture / Intercultural / Ethnography. 


\section{INTRODUCCIÓN}

La investigación versa sobre ciertas estrategias metodológicas basadas en marcos teóricos que se han utilizado en la educación superior y busca comprender los problemas de rendimiento, en este nivel educativo, de los alumnos que presentan diferencias culturales; específicamente se ha analizado un caso en la Universidad Ricardo Palma, en el primer ciclo del Programa de Estudios Básicos dentro del Taller de Comunicación Oral y Escrita.

Para explicar los problemas socioculturales que afectan el rendimiento académico se asumieron los siguientes modelos: el de la competencia cultural de McCarthy (1994), el sociolingüístico o el de los estilos de comunicación-interacción de David Poveda (2001) y el modelo ecológico de John Ogbu (1993).

Modelos que permiten establecer indicadores en una matriz que permita correlacionar la teoría con los aspectos que permitirán observar los problemas sobre los cuales se discute, en un caso determinado dentro del contexto académico de la Universidad Ricardo Palma, específicamente en una estudiante brasileña, con la finalidad de realizar un diagnóstico educativo sociocultural que permita mejorar, las sesiones de clase, los materiales y el lenguaje entre docente estudiante y entre pares. La técnica empleada fue el cuestionario y el instrumento fue una guía de entrevista. Después de finalizar el recojo de información, se llegó a establecer que algunos contenidos conceptuales que recibió la estudiante no fueron propios de la cultura de origen, los materiales son distintos en su estructuración al de su país de origen y el nivel de interrelación social se encuentra limitado. Los resultados permitirán realizar la investigación - acción para solucionar los problemas detectados.

Es necesario aclarar que estos modelos son asumidos por investigadores de distinta procedencia disciplinar (sociólogos, sociolingüistas, psicólogos, docentes, psicopedagogos, etc.), no solo por profesores, sin embargo a partir de estos se pretende dar explicación a los problemas socioculturales que pueden presentarse en estudiantes del nivel superior y que puedan afectar su rendimiento académico. Esta explicación pretende abordar (directa o indirectamente) el problema educativo de por qué fracasan o tienen rendimiento no esperado algunos estudiantes de otra procedencia cultural y lingüística en una universidad peruana, que por lo general constituye una minoría étnica dentro de un campus universitario. 
De acuerdo a los modelos asumidos, se pueden analizar ciertos factores que generan problemas socioculturales que afectan al rendimiento. Por esa razón se decidió qué debía observarse y bajo qué modelo se haría. Se optó por lo siguiente:

- De acuerdo al Multicultural, se puede observar los contenidos del currículum, de los cuales se asumen:

a. Contenidos conceptuales

b. Materiales empleados

c. Prejuicios en los docentes y estudiantes

- De acuerdo al Sociolingüístico/Instrumento de mediación social: se puede evaluar los modos de aprendizaje y la lengua:

a. Usos lingüísticos: morfosintaxis y vocabulario

b. Formatos narrativos

c. Estilos de aprendizaje: instrucciones verbales, estructuras de participación

- De acuerdo al modelo Ecológico se pueden observar las prácticas y eventos letrados:

a. Intercambio comunicativo maestro-estudiante

b. Intercambio comunicativo estudiante-estudiante

Estos aspectos delimitados nos permitieron observar elementos personales de alumnos y docentes que muchas veces no son asumidos por una institución educativa y que son los que repercuten directamente en el rendimiento o que generan diversos conflictos. Por ejemplo la falta de formación de comunicación intercultural en los docentes puede descontextualizar su práctica educativa. Los modelos van a evidenciar que existen factores socioculturales en la escuela que no se asumen en el proceso educativo y que se necesita la intervención de la investigaciónacción pedagógica.

\section{BASES TEÓRICAS}

Para el desarrollo de esta pequeña investigación asumimos varios modelos teóricos como los que se presentan a continuación:

\section{EL MODELO DE COMPETENCIA CULTURAL}

El modelo se enmarca en lo que sostiene McCarthy Cameron (1994) y que en Norteamérica se denomina multiculturalismo y, en Europa, 
suele llamarse interculturalidad. Mac Carthy lo denomina "comprensión cultural", como las diferencias culturales que tanto los estudiantes como docentes deben ser sensibles y deben respetar. Estas diferencias se refieren a la existencia de grupos étnico/nacionales de los que provienen los alumnos "minoritarios" y la sociedad "mayoritaria" en que están insertos, así como a las diferencias culturales como una cuestión a incorporar al currículum, principalmente, en la forma de contenidos étnicos-nacionales Mc Carthy (1994) establece al respecto:

1. El modelo de la comprensión cultural consisten en plantear que los estudiantes y profesores deberían ser más sensibles o tolerantes hacia las diferencias étnicas/nacionales existentes en una institución educativa y propone la mejora de la comunicación entre los diferentes grupos, lo que implica un enriquecimiento de todos los estudiantes y/o de la sociedad en general.

Consideramos que es importante esta mejora en la comunicación que se establecen entre esos elementos porque influye necesariamente en el rendimiento académico, sobre todo en el rendimiento de las minorías insertas en un contexto socioeducativo de las mayorías. La mejora de la comunicación radica en primera instancia, siguiendo a Mac Carthy en la erradicación de los prejuicios hacia ellos.

2. La inclusión de contenidos "culturales" en los currículos académicos, como una posición que afirma que el multiculturalismo o interculturalismo en la educación debe ir más allá de la promoción de la comprensión cultural y de la consciencia de que existen grupos étnicos/nacionales: "Los profesores deben ayudar a los alumnos a desarrollar su identidad étnica y/o su competencia en más de un sistema cultural. Mediante la integración en los currículos del idioma y la cultura de diversos grupos étnicos/nacionales, se espera, por un lado, que la escuela contribuya a tender puentes entre ellos y, por otro, que los alumnos pertenecientes a minorías adquieran competencias en la cultura dominante, pero no a expensas de la propia "herencia cultural", que debe ser conservada y fomentada" (Mac Carthy, 1994)

Por lo tanto, no se trata solo de insertar una temática de comunicación intercultural, sino de asumir la presencia en todo contexto curricular de una interculturalidad, es decir: el contenido del mensaje en la sesión de aprendizaje, el material, la forma de enseñar, etc. 


\section{EL MODELO SOCIOLINGÜÍSTICO}

David Poveda (2001) presenta en su artículo publicado en Gazeta de Antropología, $\mathrm{N}^{\mathrm{o}}$ 17, una explicación muy significativa del modelo sociolingüístico y expone en él las ideas más importantes del sustento teórico, y se transcriben a continuación algunas citas de ese texto:

1. "La enseñanza-aprendizaje es principalmente un proceso comunicativo basado en la interacción social. Para el alumno participar en este proceso supone realizar una doble tarea y ser competente en dos dimensiones: una centrada en los contenidos de aprendizaje y otra en el formato de interacción-comunicación en el que se insertan esos contenidos (Erickson 1982). El formato de interacción-comunicación en la escuela está constituido por elementos tales como: a) los usos lingüísticos que son pertinentes (referidos a la morfosintaxis, vocabulario...), b) formatos narrativos (temático/temático asociativo), c) estilos de aprendizaje (observación/instrucciones verbales, etc.), d)estructuras de participación, entendiendo por estructura de participación, en la acepción que le otorga originalmente Susan Philips, la constelación de normas, derechos mutuos y obligaciones sociales que conforman las relaciones sociales, determinan las percepciones de los participantes de qué está ocurriendo en un intercambio comunicativo, e influyen en el resultado de la comunicación y, por tanto, en el aprendizaje; o, en la definición de Frederick Erickson (1993: 327), como la articulación de los diferentes roles en la interacción, unos roles que "conllevan pautas en lo referente al intercambio de turnos de palabra entre compañeros que interactúan, vinculan desde el punto de vista semántico pares de turnos en secuencias pregunta-respuesta, y coordinan el comportamiento del oyente relacionándolo con el del hablante" (Poveda, 2001, Gazeta de Antropología $\mathrm{N}^{\circ} 17$ ).

2. Las escuelas y las aulas son entornos comunicativo-interactivos peculiares que demandan nuevos aprendizajes conceptuales y sociales para todos los alumnos que entran en ellas. No obstante, por varias razones históricas y políticas, la distancia entre los conocimientos previos del alumno y las exigencias de la escuela es diferente para distintos grupos socioculturales". En concreto, cuando los alumnos de clase trabajadora y grupos minoritarios entran en la escuela se enfrentan a una serie de situaciones y eventos comunicativo-interactivos extraños que requieren un grado considerable de aprendizaje. Además, estos nuevos eventos pueden ser experimentados / percibidos tanto de modo "neutral", en que son novedosos pero participar en ellos no implica 
ningún conflicto sociocultural, como "problemático", en que participar en ellos comporta asumir valores y conductas culturales contrarias a las adquiridas en el contexto familiar-comunitario. (Poveda, 2001, Gazeta de Antropología $\mathrm{N}^{\mathrm{o}}$ 17).

3. Los problemas en la gestión de la comunicación pueden tener implicaciones muy importantes para el desarrollo del proceso de enseñanza-aprendizaje. La clave radica en que, dado que para los docentes el componente social de la enseñanza-aprendizaje con frecuencia es transparente (Philips 1972), cuando un alumno de un grupo minoritario experimenta estos problemas suele interpretarse en términos individuales: como un problema de personalidad (hiperactividad, timidez, pasividad, etc,), cognitivo (retraso intelectual o lingüístico) o de déficit. Son numerosos los estudios etnográficos, sobre todo norteamericanos, que se han llevado a cabo siguiendo este modelo teórico -metodológico. El pionero es el de Susan Philips (1972), donde aparece por primera vez la expresión "estructura participante", que posteriormente será traducida por estructura de participación. Philips compara una clase dirigida por un maestro indio y otra por uno anglosajón en una reserva india de Oregón, cotejando ambas con el proceso de socialización de la comunidad de donde provenían los alumnos. El maestro indio fomentó un clase con participación del equipo y donde todos se ayudaban hasta aprender la tarea, en cambio e docente anglosajón solo exponía a los estudiantes a seguir órdenes; esto devino que los estudiantes indios no siguieran las instrucciones y sean reprimidos por la docente. Los niños estaban acostumbrados, por su cultura a no dejar de hacer su trabajo independientemente de las instrucciones del docente. (Poveda, 2001, Gazeta de Antropología $\mathrm{N}^{\circ}$ 17).

Según Bertely en Poveda (2001), los niños de esta comunidad acostumbran a resolver sus problemas de manera autónoma, imitando a los adultos y sin ayuda de los mismos. Desde pequeños aprenden a través de la observación atenta de las actividades adultas y no es usual que reciban instrucciones verbales acerca de lo que deben hacer o cómo realizarlo. Por esa razón no seguían las órdenes del maestro anglosajón. Además, los niños viven en un ambiente de respeto considerable por parte de los adultos. Al convertirse en miembros útiles desde pequeños, gozan de una independencia inconcebible en el mundo occidental, no precisando pedir permiso a sus padres para hacer algo o ir a alguna parte, como el irse a dormir con algún pariente o amigo. 
En definitiva el modelo sociolingüístico propone que a nivel de la intervención educativa se debe disminuir la discontinuidad entre escuela y medio sociocultural de origen integrando esta cultura al currículo educativo de las mayorías como estructuras de participación, estilo para fomentar el aprendizaje, sobre todo a través del aprendizaje colaborativo así como la mejora en el contenido semántico de los mensajes que se transmiten en las explicaciones de las clases. Esto implica mejorar nuestros usos lingüísticos, evitar actitudes lingüísticas peyorativas. Se puede observar, por ejemplo en la actualidad, estos desajustes dentro de las aulas universitarias cuando se cuenta con convenios que establece intercambio estudiantil, donde estudiantes de otros países llegan a compartir un ciclo académico con estudiantes peruanos.

\section{EL MODELO ECOLÓGICO}

Otros contextos, distintos a los asumidos por los anteriores modelos, atiende el modelo ecológico de Jhon Ogbu, sobre todo cuando el fracaso se debe a las estrategias sociales y económicas desplegadas en los centros de estudio por la minoría o la mayoría función de la estructura de oportunidades existentes en la sociedad. En Etnografía escolar. Una aproximación a nivel múltiple (Ogbu, 1993), traducida por Honorio Velasco, observó los conflictos académicos en una serie de circunstancias de carácter políticoideológico, ya que en este modelo el éxito o fracaso académico de los estudiantes está determinado por el proceso de la docencia: normas, roles, formas de comportamiento esperable en el aula.

Ogbu evaluó los aspectos mencionados a través de una serie de investigaciones, que se presentan en la traducción realizada por Honorio Velasco en 1993:

La vía actual hacia el intercambio comunicativo maestro-alumno parece mostrar por primera vez cómo las diferencias culturales y lingüísticas pueden contribuir al fracaso escolar. (Ogbu, 1993, p. 155).

No obstante sospechamos que algunas de las conductas que tienen los niños negros en el aula, y que han sido registradas en algunas microetnografías, son debidas a la incongruencia que se da entre las habilidades y actitudes de supervivencia previamente aprendidas y las demandas del aprendizaje escolar. (Ogbu, 1993, p. 168). 
Podemos deducir de las citas que se ignoran las influencias del entorno socio políticos educativos que son realmente responsables de las pautas de los procesos que se establecen dentro de un aula de estudios. Las estructuras económicas generan o no las oportunidades para el acceso a una educación de calidad porque establecen los usos estratégicos de la institución educativa que necesariamente influyen en el comportamiento de los estudiantes y maestros en todo nivel. Además, al acceder a una educación de calidad se asume en el futuro una mejor situación económica y social.

\section{PROCEDIMIENTO METODOLÓGICO}

En base a los principios de los modelos presentados ( Mac Carthy, David Poveda y Ogbu) se ha planteado una matriz que permita correlacionar la teoría con los aspectos que permitirán observar los problemas sobre los cuales se discute, en un caso determinado dentro del contexto académico de la Universidad Ricardo Palma, con la finalidad de realizar un diagnóstico educativo sociocultural que permita mejorar, sobre todo, la mejora de las sesiones de clase, los materiales y el lenguaje entre docente estudiante y entre pares. Para lo cual se aplicó una entrevista a una estudiante brasileña, que en la actualidad estudia Arquitectura.

Para la entrevista se estructura un cuestionario a partir de los principios básicos de los modelos estudiados, de modo que nos permita una observación más rigurosa del fenómeno. Estos principios nos permitieron establecer tres dimensiones, luego los indicadores para cada dimensión que darían las pautas para establecer el tipo de ítem a realizar y que se convertirían en las preguntas del cuestionario que se aplicó en la entrevista.

\begin{tabular}{|c|c|c|}
\hline Modelo Teórico & Dimensiones & Indicadores \\
\hline $\begin{array}{l}\text { Multicultural (Mac Car- } \\
\text { thy) }\end{array}$ & Contenidos del currículum & $\begin{array}{ll}\text { a. } & \text { Contenidos conceptuales } \\
\text { b. } & \text { Materiales empleados } \\
\text { c. } & \text { Prejuicios en los docentes y } \\
& \text { estudiantes }\end{array}$ \\
\hline Sociolingüístico (Poveda) & $\begin{array}{l}\text { Instrumento de mediación so- } \\
\text { cial: } \\
\text { Modos de aprendizaje y la len- } \\
\text { gua }\end{array}$ & $\begin{array}{l}\text { a. Usos lingüísticos: morfosin- } \\
\text { taxis y vocabulario } \\
\text { b. Formatos narrativos } \\
\text { c. Estilos de aprendizaje: ins- } \\
\text { trucciones verbales, estruc- } \\
\text { turas de participación }\end{array}$ \\
\hline Ecológico (Ogbu) & $\begin{array}{l}\text { Prácticas sociales y eventos le- } \\
\text { trados }\end{array}$ & $\begin{array}{ll}\text { a. Intercambio comunicativo } \\
\text { maestro-alumno } \\
\text { b. Intercambio comunicativo } \\
\text { alumno-alumno }\end{array}$ \\
\hline
\end{tabular}


Con esta articulación se elaboró la matriz operativa para la producción de ítems que se presenta a continuación:

\begin{tabular}{|c|c|}
\hline Indicadores & Ítem para el cuestionario \\
\hline $\begin{array}{l}\text { a. Contenidos conceptuales } \\
\text { b. Materiales empleados } \\
\text { c. Prejuicios en los docentes y estudiantes }\end{array}$ & $\begin{array}{l}\text { 1. ¿Consideras que los contenidos del sílabo } \\
\text { no son propios de la cultura de origen? } \\
\text { ¿Por qué? } \\
\text { 2. ¿Consideras que los formatos de los } \\
\text { materiales educativos no siguen las } \\
\text { pautas de tu país de origen? } \\
\text { ¿Esta situación influye en tu rendimiento? } \\
\text { 3. ¿Estás de acuerdo con la forma en que los } \\
\text { docentes y estudiantes asumen tu origen? }\end{array}$ \\
\hline $\begin{array}{l}\text { a. Usos lingüísticos: morfosintaxis y vo- } \\
\text { cabulario } \\
\text { b. Formatos narrativos } \\
\text { c. Estilos de aprendizaje: instrucciones } \\
\text { verbales, estructuras de participación }\end{array}$ & $\begin{array}{l}\text { 4. ¿Encuentras interferencias lingüísticas } \\
\text { morfosintácticas o del léxico del portugués } \\
\text { respecto al español que usas en el aula? } \\
\text { 5. ¿Consideras que las interferencias } \\
\text { lingüísticas que has descrito generan } \\
\text { algún tipo de fracaso académico? } \\
\text { 6. ¿Las estructuras textuales son semejantes } \\
\text { o no respecto a las de tu lengua de origen? } \\
\text { ¿Consideras que las formas de las estructu- } \\
\text { ras narrativas y expositivas son distintas? } \\
\text { 7. ¿Las instrucciones que recibes de tu } \\
\text { maestro(a) son fácilmente entendibles } \\
\text { y te permiten desarrollar la actividad } \\
\text { académica con éxito? ¿Por qué? } \\
\text { 8. ¿La forma como participas en tu } \\
\text { aprendizaje sigue patrones conocidos o } \\
\text { distintos? ¿Influye en tu éxito académico? }\end{array}$ \\
\hline $\begin{array}{l}\text { a. Intercambio comunicativo maestro- } \\
\text { alumno } \\
\text { b. Intercambio comunicativo alumno- } \\
\text { alumno }\end{array}$ & $\begin{array}{l}\text { 9. ¿La forma en que el maestro peruano } \\
\text { busca comunicarse con el estudiante, en } \\
\text { este caso contigo, constituye una práctica } \\
\text { sociocultural distinta a la que usualmente } \\
\text { estuviste expuesto? ¿Favorece o } \\
\text { desfavorece tu rendimiento académico y } \\
\text { tu incorporación a esta sociedad? } \\
\text { 10. ¿La forma en que el compañero(a) peruano } \\
\text { busca comunicarse contigo, constituye } \\
\text { una práctica sociocultural distinta a la que } \\
\text { usualmente estuviste expuesto? ¿Favorece } \\
\text { o desfavorece tu rendimiento académico y } \\
\text { tu incorporación a esta sociedad? }\end{array}$ \\
\hline
\end{tabular}


Los ítems fueron aplicados a una estudiante brasileña quien recibió las mismas sesiones de clase que un estudiante peruano.

Entrevista aplicada a una estudiante brasileña en la Universidad Ricardo Palma en el Curso Taller de Comunicación Oral y Escrita que se transcribe de una grabación:

1. ¿Consideras que los contenidos del sílabo no son propios de la cultura de origen? ¿Por qué?

Solo algunos contenidos, porque otros sí los conozco en alguna medida por la escuela. Los que no son propios a mis costumbres sobre todo, porque considero que nuestras culturas son parecidas. Por ejemplo la organización de la universidad que se revisa en las primeras semanas de clase es distinta, parece que en este país hay una preocupación por darnos a entender que estamos en la universidad y no en la escuela. Sobre todo en la universidad del Perú, porque en mi país no se ve estas cosas. Estas primeras semanas de clase no las comprendí porque no conozco el funcionamiento de la universidad peruana, me pedían que reflexione sobre la labor de nosotros en cuanto a la ley universitaria, pero para mí fue difícil porque es una ley distinta a la de mi país. Tuve que pedir ayuda a la profesora.

2. ¿Consideras que los formatos de los materiales educativos no siguen las pautas de tu país de origen? ¿Esta situación influye en tu rendimiento?

En alguna medida, porque todo está en español que no es igual al portugués aunque lo entiendo bastante, sin embargo tengo que preguntar muchas cosas a mis compañeros, hay muchas palabras que no conozco, son propias del español y no del portugués. Creo que se dieron cuenta por eso que no era de aquí. Me afecta porque demoro en realizar las actividades hasta que me dé cuenta del significado de lo que se pide en la actividad. Pero es comprensible porque son materiales para los que hablan español del Perú.

3. ¿Estás de acuerdo con la forma en que los docentes y estudiantes asumen tu origen?

Sí, porque no he sentido ningún tipo de rechazo, aunque cuando intervengo porque la profesora se ha preocupado mucho porque lo haga, mis compañeros me observan con detenimiento y algunos se sonríen cuando no puedo pronunciar algunas palabras con muchas sílabas, pero no se burlan más creo que se sienten asombrados, además la profesora le gusta que participe. No buscan apartarse de mí. 
4. ¿Encuentras interferencias lingüísticas morfosintácticas o del léxico del portugués respecto al español que usas en el aula?

Cuando la profesora comienza a explicar, a veces me pierdo porque no entiendo algunas palabras ya que se habla muy fluido. Sobre todo el problema está en muchas palabras que no conozco, porque son del lugar, por otro lado están algunas consonantes y vocales que no se pronuncian como yo las hago. Tengo algunas dificultades pero ya estoy aprendiendo. En el material del curso hay mucho léxico que no conozco.

5. ¿Consideras que las interferencias lingüisticas que has descrito generan algún tipo de fracaso académico?

No siento fracaso pero demoro en leer las separatas, a veces para acortar tiempo debo trasladarla con el google traductor al portugués, aunque no siempre me da una buena traducción. Porque si demoro, no cumplo a tiempo con los trabajos y eso sí sería un fracaso para mí. Puede ser que otros estudiantes extranjeros sí tengan problemas, por ejemplo los de origen chino que estudian aquí también. En alguna medida el español se parece al portugués. Algunos verbos no los entiendo porque se escriben distintos en portugués también la manera en que se ordenan las palabras.

6. ¿Las estructuras textuales son semejantes o no respecto a las de tu lengua de origen? ¿Consideras que las formas de las estructuras narrativas y expositivas son distintas?

Sí son distintas, aquí siempre el profesor o el texto da una introducción al asunto, no solo en el texto de especialidad sino en las historias. Cuando he leído textos en mi escuela comenzamos la historia de frente, son muy cortas. Aquí estoy leyendo una obra literaria que tengo que leer varias veces el inicio porque no sé por qué no va de frente al contenido, creo que debo entender esto para seguir.

Por ejemplo recuerdo esta historia en mi lengua:

Sempre gostei de caminhar sobre a areia da praia, e faço-me acompanhar, sempre, da minha força, penso e repenso, sobre tudo aquilo que me possa parecer um obstáculo.....certo dia reparei que as pegadas eram só duas ¡Tinha sido abandonado pela minha própria força! Nunca mais fui o mesmo, ate que agora que a encontrei, perguntei-lhe....ó força ¿porque e que me abandonaste quando mais precisei de ti? E ela respondeu-me.... eu não te abandonei, eu andei foi contigo ao colo estes anos todos.... 
Traducido al español en forma literal sería:

Siempre he disfrutado de caminar en la playa, y me hacen seguir, una vez más, de mi fuerza, yo pienso y repensar acerca de cualquier cosa que podría parecer un obstáculo para mí.....un día me di cuenta de que las huellas eran sólo dos iHabía sido abandonado por mi propia fuerza! Nunca había estado en la misma, hasta ahora que lo encontré, le pregunté por qué y fuerza.... ¿O me has abandonado cuando más te necesitaba? Y ella me respondió.... Yo no te he abandonado, caminé con usted a la vuelta ha sido todos estos años...

Como puede observar, cuando se traduce en español, los órdenes de las palabras cambian. Por otro lado he tenido que preguntar a mis compañeros cuál es la utilidad de cierta parte del texto que se usa como material del curso. Cuando ellos me indican que ciertas partes del texto me preparan para entender lo que sigue, entonces me doy cuenta que el texto es muy útil. En mi escuela todo me lo explicaba mi maestra.

7. ¿Las instrucciones que recibes de tu maestro(a) son fácilmente entendibles y te permiten desarrollar la actividad académica con éxito? ¿Por qué?

No las entiendo al comienzo, tengo que llamar al profesor(a) para que me vuelva a explicar. Por un lado debido a la lengua y a lo rápido que pueda hablar, pero por otro lado porque no todos los docentes son claros, algunos solo te indican que hagas la actividad y no te dan más explicación. Algunos docentes no saben que soy brasileña hasta que me acerco y trato de pedir su ayuda, creo que por eso no explican.

8. ¿La forma como participas en tu aprendizaje sigue patrones culturales, sociales conocidos o distintos? ¿Influye en tu éxito académico?

Me gusta esta universidad, aquí veo todo tipo de gente en un aula, peruanos, extranjeros. En Brasil no es así. Hay escuelas solo para gente con mucho dinero y otras para gente de clase media o baja, todo está bien diferenciado. En algunos colegios los docentes enseñan poco y tenemos que llevar mucha tarea a casa. En otros colegios hay mucho peligro por la zona en que se encuentra, allí casi no hay profesores pero sí instructores. Las universidades brasileñas son muy buenas pero no todos pueden ingresar a estudiar porque tienen que trabajar, he visto más gente extranjera en una universidad brasileña. Aquí, en Perú, es distinto. 
En un aula todos deben participar, muchos profesores lo piden pero los alumnos no desean participar, yo sí trato de participar siempre porque así aprendo más de esta cultura. Veo mucho interés por los profesores para que aprendamos y esto me ayuda bastante para adaptarme. Creo que depende de mí. Algunos docentes no insisten en que aprendas y en estos cursos sí tengo problemas, porque estos docentes a veces me miran y no me contestan, creo que es por el tiempo que tienen. En estos cursos tengo notas bajas.

9. ¿La forma en que el maestro peruano busca comunicarse con el estudiante, en este caso contigo, constituye una práctica sociocultural distinta a la que usualmente estuviste expuesto? ¿Favorece o desfavorece tu rendimiento académico y tu incorporación a esta sociedad?

Sí porque el docente aquí espera que el estudiante le pregunte o se acerque, no es muy práctico y la mayor actividad es individual, en Brasil se trabaja mucho en equipo y hay muchos tutores. Aquí no veo mucho eso. Creo que debería haber un departamento que vigile nuestros problemas académicos ya que incluso veo estudiantes chinos y algunos franceses. Los chinos tienen más problemas que yo porque siempre los veo con su traductor digital en la mano.

10. ¿La forma en que el compañero(a) peruano busca comunicarse contigo, constituye una práctica sociocultural distinta a la que usualmente estuviste expuesto? ¿Favorece o desfavorece tu rendimiento académico $y$ tu incorporación a esta sociedad?

Sí, en Brasil como que somos más habladores y divertidos con todos. Aquí si no eres su amigo no te hablan. Primero tengo que tratar de hacer amigos y luego pedirles ayuda. A veces una trata de acercarse pero no te toman importancia. El primer año que estuve en Perú me fue difícil porque me sentía sola, ahora ya estoy en cuarto ciclo y me estoy adaptando y mejorando mis notas. Ya sé que las fiestas aquí son cuando lo desean los compañeros y por lo general no puedo ir, esto limita a que tenga amigos, pero me estoy acostumbrado. Creo que poco a poco me iré adaptando y mejoraré en todo. Sé que en Perú hay universidades estatales, la universidad Ricardo Palma es privada, por eso puedo sentir que tengo de todo aquí, imagino que otros tal vez no tengan todo esto. Llegué a Perú porque mi papá fue contratado como ingeniero para construir la vía del Rímac. 


\section{RESULTADOS}

De acuerdo a la entrevista realizada en la estudiante como unidad de análisis, así como a sus respuestas se llega a los siguientes resultados:

1. Algunos contenidos conceptuales que recibió la estudiante no fueron propios de la cultura de origen, los materiales son distintos en su estructuración y el nivel de interrelación social se encuentra limitado.

2. Hay un desajuste respecto al medio sociolingüístico de origen:

a. Estilos de aprendizaje- teoría/ práctica: sobre todo la forma como se dirige el docente a los estudiantes, da instrucciones generales asumiendo que todos entienden.

b. Usos lingüísticos diferentes: lenguaje muy fluido de docentes y compañeros, léxico desconocido, pronunciación de las palabras.

c. Trabajo en equipo frecuente en el país de origen, frente a los trabajos individuales y sin ningún apoyo en la universidad peruana.

3. Las situaciones comunicativas, los usos, formas de relacionarse con el docente son distintos y necesitan acomodo solo por parte del estudiantes. Los compañeros de clase no son fáciles de abordar, el extranjero debe ajustarse patrones de comportamiento al que no está acostumbrado y al acceso a las prácticas de la comunidad se vuelven limitadas.

De acuerdo a los modelos asumidos se presentan de manera articulada los resultados para realizar las propuestas de intervención que podrías asumirse a través de la investigación acción:

\begin{tabular}{|c|l|l|l|}
\hline $\begin{array}{c}\text { Modelo } \\
\text { asumido }\end{array}$ & \multicolumn{1}{c|}{$\begin{array}{c}\text { Característica } \\
\text { resultante }\end{array}$} & $\begin{array}{c}\text { Estrategia } \\
\text { educativa (in- } \\
\text { tervención) }\end{array}$ & \multicolumn{1}{c|}{$\begin{array}{c}\text { Investigación } \\
\text { acción (área) }\end{array}$} \\
\hline Multicultural: & $\begin{array}{l}\text { Algunos contenidos } \\
\text { conceptuales no son } \\
\text { propios de la cultura } \\
\text { currículum } \\
\text { de origen de los es- } \\
\text { tudiantes brasileños, } \\
\text { los materiales son } \\
\text { distintos y el nivel de } \\
\text { interrelación social se } \\
\text { encuentra limitado. }\end{array}$ & $\begin{array}{l}\text { Evaluación de } \\
\text { pos culturales }\end{array}$ & $\begin{array}{l}\text { Investigar sobre la } \\
\text { existencia de pre- } \\
\text { juicios en los profe- } \\
\text { sores y estudiantes. } \\
\text { Estereotipos en los } \\
\text { materiales educati- } \\
\text { vos y cómo tratar- } \\
\text { los. }\end{array}$ \\
\hline
\end{tabular}




\begin{tabular}{|c|c|c|c|}
\hline $\begin{array}{c}\text { Sociolingüís- } \\
\text { tico: } \\
\text { Instrumento } \\
\text { de mediación } \\
\text { social: } \\
\text { Modos de } \\
\text { aprendizaje y la } \\
\text { lengua }\end{array}$ & $\begin{array}{l}\text { Desajuste respecto al } \\
\text { medio sociolingüístico } \\
\text { de origen: } \\
\text { a. Estilos de aprendi- } \\
\text { zaje: teoría/ práctica: } \\
\text { sobre todo la forma } \\
\text { como se dirige el do- } \\
\text { cente a los estudiantes. } \\
\text { b. Usos lingüísticos di- } \\
\text { ferentes: lenguaje muy } \\
\text { fluido, léxico descono- } \\
\text { cido, pronunciación de } \\
\text { las palabras. } \\
\text { c. trabajo en equipo } \\
\text { frente a los trabajos } \\
\text { individuales y sin nin- } \\
\text { gún apoyo. }\end{array}$ & $\begin{array}{l}\text { Incorporación } \\
\text { de estructuras } \\
\text { de participa- } \\
\text { ción propios } \\
\text { de la cultura } \\
\text { de origen in- } \\
\text { dependiente- } \\
\text { mente de que } \\
\text { se incorpo- } \\
\text { ren o no a los } \\
\text { contenidos de } \\
\text { aprendizaje }\end{array}$ & $\begin{array}{l}\text { Investigar de cómo } \\
\text { usamos el saber o } \\
\text { cómo nos relaciona- } \\
\text { mos con ellos y qué } \\
\text { semejanzas lingüís- } \\
\text { ticas podría usarse } \\
\text { como estrategia de } \\
\text { mediación. }\end{array}$ \\
\hline $\begin{array}{c}\text { Ecológico: } \\
\text { Prácticas y } \\
\text { eventos letrados }\end{array}$ & $\begin{array}{l}\text { Las situaciones co- } \\
\text { municativas, los usos, } \\
\text { formas de relacionarse } \\
\text { con el docente son dis- } \\
\text { tintos y necesitan aco- } \\
\text { modo solo por parte } \\
\text { del estudiantes. } \\
\text { Los compañeros de } \\
\text { clase no son fáciles de } \\
\text { abordar, el extranjero } \\
\text { debe ajustarse patro- } \\
\text { nes de comportamien- } \\
\text { to al que no está acos- } \\
\text { tumbrado y al acceso a } \\
\text { las prácticas de la co- } \\
\text { munidad es limitado. }\end{array}$ & $\begin{array}{l}\text { Estrategias } \\
\text { que involu- } \\
\text { cren signifi- } \\
\text { cativamente } \\
\text { los eventos } \\
\text { letrados y jus- } \\
\text { tifiquen las } \\
\text { prácticas le- } \\
\text { tradas como } \\
\text { fenómenos de } \\
\text { integración. }\end{array}$ & $\begin{array}{l}\text { Optimización cul- } \\
\text { tural: incorpora- } \\
\text { ción de lo habitual } \\
\text { y reconsideración } \\
\text { de aspectos incluso } \\
\text { económicos y de } \\
\text { accesibilidad. }\end{array}$ \\
\hline
\end{tabular}

\section{CONCLUSIONES Y PROPUESTAS DE INTERVENCIÓN- INVES- TIGACIÓN}

De acuerdo a lo analizado se concluye que el sistema aplicado en el ámbito universitario necesita de una transformación no solo a nivel de contenidos sino de estrategias y valores que rijan las relaciones interpersonales. Es necesario que los patrones de miradas que acostumbran 
aplicar los docentes hacia el rendimiento o actitudes de los estudiantes estén basados en una formación y/o capacitación intercultural no solo disciplinar.

La educación superior, en el mundo globalizado en el que vivimos, debe procurar una mirada a los grupos minoritarios dentro de un ambiente donde la hegemonía de la clase mayoritaria rige todos los procedimientos académicos, tal como sucede en la actualidad.

Desde la perspectiva teórico-metodológica, en la que se ha analizado el caso de la estudiante brasileña y que se recomienda confirmar con otros estudiantes extranjeros, se llega a evidencia que existe una discontinuidad familia-comunidad-universidad que genera dificultades para el rendimiento académico y las interrelaciones en el aula, existen desajustes que se dan entre "estructuras de participación", "usos lingüísticos" y/ "estilos de aprendizaje".

\section{PROPUESTAS DE SOLUCIÓN PARA LO ANALIZADO}

Solución 1. Se necesita la transformación de contenidos de forma que no resulten tan discrepantes con las actividades con las cuales estuvieron acostumbrados los estudiantes extranjeros ya que éstas referían a contextos étnicos distintos a los que estos se enfrentan en su nueva realidad académica. Lo que conlleva a la superación de prejuicios étnicos y al desarrollo del sentido de autoeficacia al mejorar los procesos de comparación intrapersonal e interpersonal cuando se desea emitir juicios de valor frente a los resultados académicos.

Solución 2. Una óptima distribución del éxito y del reconocimiento que favorezca la motivación por el aprendizaje unida a la tolerancia frente a la diversidad en los niveles cognitivos, emocionales y conductuales. La distribución del reconocimiento debe darse no solo para la clase mayoritaria sino también para la minoritaria.

Solución 3: La inclusión de contenidos culturales en los currículos tendrá un efecto positivo en los estudiantes representantes de las minorías $\mathrm{y}$, por tanto, también en su rendimiento académico. En este aspecto debe estudiarse cuáles son los contenidos que se incluyen en las diversas materias o asignaturas y cómo los tratan los profesores, en qué idioma se imparten las clases, cómo buscar un lenguaje que sirva como puente intercultural e interlinguistico (por ejemplo instrucciones más estándar a nivel de equipo y más específicas a nivel individual). Porque la cuestión 
del bajo rendimiento de las minorías se relaciona con la actitud prejuiciosa por parte de los docentes/otros alumnos y con la no presencia de la cultura minoritaria en el currículum escolar; por lo tanto las políticas/intervenciones socioeducativas que respetan/fomentan las identidades culturales de las minorías tendría un efecto positivo en el rendimiento académico de los alumnos pertenecientes a ellas. Ese auto concepto que se logre facilitaría la «motivación» para el aprendizaje significativo. Por ejemplo se puede plantear un currículum multi /intercultural, que incluya conocimientos sobre la historia, antecedentes y los logros de las minorías para reducir la descontextualización de los contenidos especializados. En este aspecto podemos realzar la presencia del Instituto Confucio en la Universidad Ricardo Palma, que coloca a disposición de docentes y estudiantes, una serie de textos escritos en español pero con contenidos de la cultura china.

Solución 4.- El lenguaje, la interacción y la comunicación son conductas y conocimientos culturales que se adquieren en el contexto en el cual se vive o se convive y muchas veces son el resultado de un proceso de socialización familiar y/o de la comunidad. A nivel universitario, los estudiantes ya ingresan con paradigmas sociales y culturales, es decir comportamientos y/o maneras de reaccionar arraigadas en la comunidad donde ha desarrollado todos sus años de niñez y adolescencia. Entre el adulto y el adolescente o niño se establecen formas de interacción, como entre miembros de la familia; estas formas son traídas a los ámbitos educativos a los cuales se verá expuesto después, en su formación profesional. Por eso es necesario que el docente conozca de estos rasgos culturales y sociales para incorporarlos en sus sesiones de aprendizaje en forma sutil de modo que promueva un clima donde el estudiante de la minoría no se sienta excluido y sin saber cómo acercarse al estudiante del grupo mayoritario.

Se evitaría así no solo la descontextualización de los contenidos sino que se evitarían las "valoraciones clínicas" que según Bertely $(1992, b)$ tanto el estilo de aprendizaje fomentado por la maestra que fue observada en su investigación (seguimiento por parte de los alumnos de instrucciones verbales) como la estructura de la participación que establece (control centralizado de la clase, la exigencia de que todos realicen las actividades al mismo tiempo y siguiendo las mismas secuencias, la exposición pública de los estudiantes por el incumplimiento de las obligaciones, etc.) son radicalmente diferentes a los que estaban acostumbrados los estudiantes de otra procedencia ética, por lo tanto se evidencia un desajuste con los que son propios que desfavorece el aprendizaje. 


\section{REFERENCIAS BIBLIOGRAFÍAS}

BERTELEY, María

1992a Adaptaciones escolares en una comunidad mazahua, en Mario Rueda y M. A. Campos (coord.). Investigación etnográfica en educación. México: UNAM.

BERTELEY, María

1992b Adaptaciones docentes en una comunidad mazahua, Nueva Antropología, $\mathrm{N}^{\mathrm{0}} 42$.

BERTELEY, María

1995 Estrategias didácticas y sujeto cultural en preescolar. En M. Arroyo Acevedo (coord.) La atención al niño preescolar. Entre la política educativa y la complejidad de la práctica. México: Fundación SNTE para la Cultura del Maestro Mexicano.

BERTELEY, María

1998 Historia social de la escolarización y uso del castellano escrito en un pueblo zapoteco migrante. Universidad Autónoma de Aguascalientes (tesis doctoral inédita).

ERICKSON, Frederick

1982 El discurso en el aula como improvisación: las relaciones entre la estructura de la tarea académica y la estructura de la participación social en clase. En Honorio Velasco et. al. Lecturas de antropología para educadores. Madrid: Trotta.

HEATH, Shirley B.

1981 Ways with words: Language, life and work in communities and classrooms. Cambridge: Cambridge University Press.

VELASCO, Honorio

1997 La lógica de la investigación etnográfica. Valladolid: Editorial Trotta

VELASCO, Honorio (Comp.)

2010 Lecturas de antropología social y cultural: la cultura y las culturas.

Madrid: UNED cuadernos. 
MC CARTHY, Cameron

1994 Racismo y currículo. La desigualdad social y las teorías y políticas de las diferencias en la investigación contemporánea sobre la enseñanza. Madrid: Morata.

OGBU, John

1993 Etnografía escolar. Una aproximación a nivel múltiple. En Honorio Velasco et. al. Lecturas de antropología para educadores. Madrid: Trotta.

PHILIPS, Susan

1972 Participant structures and communicative competence: Warm Springs children in community and classroom. En C. B. Cazden, U. P. John y D. Hymes, Functions of language in the classroom. Nueva York: Teachers College Press.

POVEDA, David

2001 La educación de las minorías étnicas desde el marco de las continuidades-discontinuidades familia-escuela. En Gazeta de Antropología, $\mathrm{N}^{\mathrm{o}} 17$. 